Available online at www.eccomasproceedia.org

Eccomas Proceedia COMPDYN (2021) 4467-4480

ECCOMAS

Proceedia
COMPDYN 2021

$8^{\text {th }}$ ECCOMAS Thematic Conference on Computational Methods in Structural Dynamics and Earthquake Engineering M. Papadrakakis, M. Fragiadakis (eds.) Streamed from Athens, Greece, 28 - 30 June 2021

\title{
CRITICAL ACCELERATION, SEISMIC SLIDING DISPLACEMENT AND SMART DESIGN OF CANTILEVER WALLS
}

\author{
Loukas C. Katsenis ${ }^{1}$, Constantine A. Stamatopoulos ${ }^{2}$, Vassilis P. Panoskaltsis ${ }^{1}$ \\ ${ }^{\mathbf{1}}$ Department of Civil Engineering, Demokritos University of Thrace, \\ University Campus Xanthi-Kimmeria, 67100 Xanthi, Greece \\ e-mails: katsenisloukas@yahoo.gr, vpanoska@civil.duth.gr \\ ${ }^{2}$ Stamatopoulos and Associates Co; Hellenic Open University; 5 Isavron str,. 11471 Athens, Greece \\ e-mail: k.stam@saa-geotech.gr
}

\begin{abstract}
Cantilever walls are a popular type of retaining system. The slip mode of failure of these retaining systems under seismic loading has recently been studied. Cantilever walls must be designed in a manner such as to minimize the seismic displacement. The "conventional" slidingblock model is the most commonly used simplified model predicting the seismic displacement of slopes for given earthquake motions. However, in dynamic analyses, usually the seismic motion is applied at the underlying bedrock and the seismic displacement along a slip surfaces depends not only on the seismic response of the slip surface, but also on the dynamic characteristics of the soil profile both above and below the slip surface. The present work proposes a cost-effective method predicting the seismic displacement of cantilever walls, and applies it for their smart design. In order to achieve the paper first proposes a method predicting the critical acceleration value of cantilever walls retaining systems by application of equations predicting the critical acceleration value for gravity walls for the slip mode of failure of these retaining systems. Then the paper proposes a method predicting the seismic displacement of cantilever walls considering the dynamic response of the underlying soil profile by applying a recently developed 1-D 2-body dynamic stick-slip method at the particular geometry of cantilever walls. Finally, based on the above, the paper proposes a cost-effective method for smart design of cantilever walls, and presents a typical example. The work illustrated that the de-amplification effect of the seismic response can be crucial if the soil underlying the wall is soft and deep and in this case a wall with a looser backfill may be preferable.
\end{abstract}

Keywords: cantilever walls, sliding-block model, dynamic response, seismic displacement, slip surface, coupled analyses, smart design 


\section{INTRODUCTION}

Engineers usually assess the seismic safety of slopes and retaining structures using the dynamic factor of safety calculated from loads. However, evaluations based on the dynamic factor of safety have the serious drawback that they do not consider the seismic displacement, which is directly related to damage and recently design of retaining structures is based on prediction of the seismic displacement along its slip surface and its comparison with the tolerable displacement that this structure can sustain [1].

Cantilever walls of $\mathrm{L}$ or inverted T-shape are a popular type of retaining system. The design exploits the stabilizing action of soil weight over the footing slab against both sliding and overturning. It is widely considered as advantageous over conventional gravity walls for it combines economy and ease in construction and installation [2]. Design of cantilever walls depends on its dimensions, but also the soil type used in the backfill, as well as its compaction. Cantilever walls must be designed in a manner such as to minimize the seismic displacement. The slip mode of failure of these earth structures under seismic loading has been studied by Kloukinas et al. [3]. However, the seismic displacement along a slip surface and, additionally, its dependence on the dynamic characteristics of the backfill and the soil profile below has not been studied.

The "conventional" Newmark sliding-block model [4], illustrated in Fig. 1, is the most commonly used simplified model predicting the seismic displacement of natural slopes and retaining structures for given earthquake motion $[1,5,6]$. As illustrated in Fig. 1a, a rigid block rests on an inclined plane. The resistance along the block-inclined plane boundary follows the MohrCoulomb law. Critical acceleration is the minimum horizontal acceleration which causes movement of the block. Every time where the applied horizontal acceleration is larger than the critical acceleration, the block slides. The total displacement is obtained by the addition of the partial slips. This model is used for the prediction of permanent seismic movement of slopes and retaining structures along a predefined slip surface, by appropriately selecting the equivalent critical and applied acceleration values of the rigid block [5]. For gravity walls, according to the Monobe-Okabe theory [7, 8], methods have been developed to determine the critical acceleration value, both by iteration [9] and analytically by first indicating the appropriate slip surface $[10,11]$.

In dynamic analyses, usually the seismic motion is applied at the underlying bedrock and the seismic displacement along a slip surfaces depends not only on the seismic response of the slip surface, but also on the dynamic characteristics of the soil profile both above and below the slip surface [12-14]. Katsenis et al., [13,14] simulated the effect of the soil profile on the seismic displacement along the slip surface using a 1-D dynamic system of 2 continuous bodies separated by a horizontal slip which simulates the seismic displacement of the conventional sliding-block model.

The present work proposes a method predicting the seismic displacement of cantilever walls, and applies it for its smart design. In particular, the simplified geometry of Fig. 2 and table 1 of a cantilever wall above a soil layer is considered. In order to achieve the paper first proposes a method predicting the critical acceleration value of cantilever walls by application of equations predicting the critical acceleration value for gravity walls given by [11] for the slip mode of failure of these retaining systems identified by [3]. Then the paper proposes a method predicting the seismic displacement of cantilever walls considering the dynamic response of the soil profile be first describing the Katsenis et al. [13] model and then applying it at the particular geometry of cantilever walls. Finally, the paper proposes smart design of cantilever walls by first presenting typical results of the Katsenis et al. $[13,14]$ model and then applying them for cantilever walls smart design. 


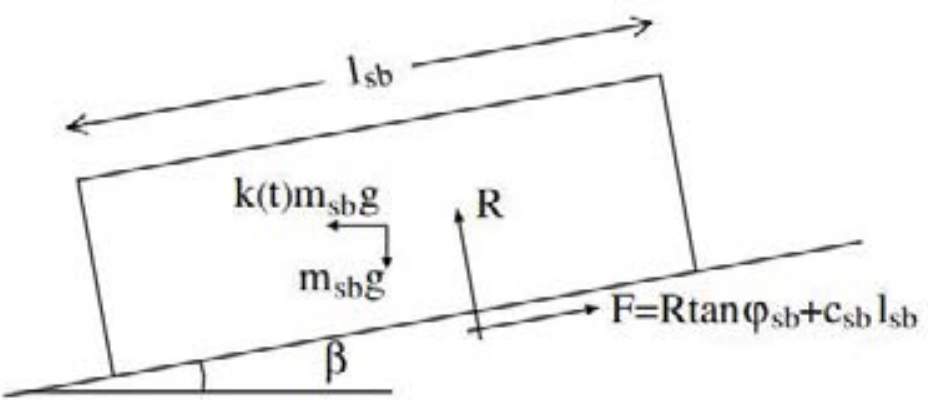

Figure 1: A block sliding in an inclined plane (the "conventional" sliding-block model

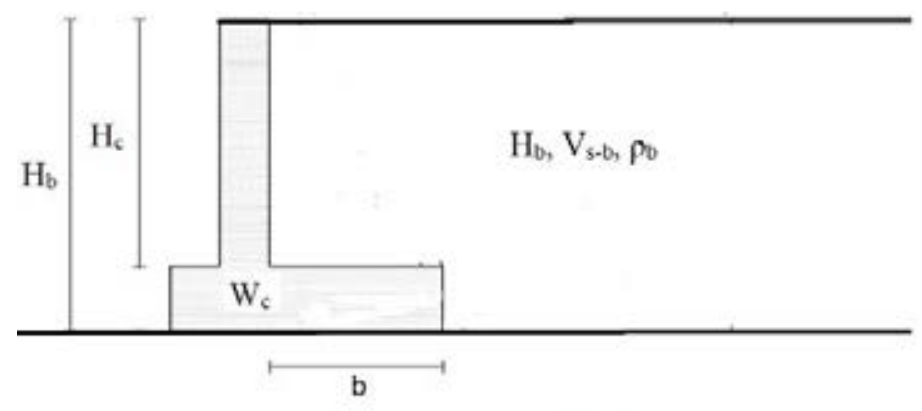

$$
\mathrm{H}_{\mathrm{s}}, \mathrm{V}_{\mathrm{ss}, \mathrm{s}} \rho_{\mathrm{s}}
$$

Figure 2: The problem considered: A canteliver wall above a soil layer

\begin{tabular}{|l|l|l|}
\hline & Parameter & Symbol \\
\hline Wall & Weight per unit length & $\mathrm{W}_{\mathrm{c}}$ \\
& Length inside backfill & $\mathrm{b}$ \\
& Height above base & $\mathrm{H}_{\mathrm{c}}$ \\
& Friction angle at base & $\varphi_{\mathrm{c}}$ \\
\hline Backfill & Height & $\mathrm{H}_{\mathrm{b}}$ \\
& Shear Wave velocity & $\mathrm{V}_{\mathrm{s}-\mathrm{b}}$ \\
& Unit weight & $\rho_{\mathrm{b}}$ \\
\hline Soil-wall interface & Friction angle & $\varphi_{\mathrm{b}}$ \\
\hline Underlying soil & Friction angle & $\varphi_{\mathrm{I}}=\varphi_{\mathrm{b}}$ \\
& Height & $\mathrm{H}_{\mathrm{s}}$ \\
& Shear Wave velocity & $\mathrm{V}_{\mathrm{s}-\mathrm{s}}$ \\
& Unit weight & $\rho_{\mathrm{s}}$ \\
\hline
\end{tabular}

Table 1: Model parameters defining the cantilever walls considered in the present study 


\section{PROPOSED METHOD PREDICTING THE CRITICAL ACCELERATION OF CANTILEVER WALLS}

\subsection{State of the art: The critical acceleration value for gravity walls}

Gravity walls are relatively rigid structures walls used for supporting soil laterally so that it can be retained (Fig. 3a). The applied force in walls under a horizontal acceleration value is estimated by the Mononobe-Okabe equation [7, 8], and typically iteration is performed to estimate the estimate the critical acceleration causing failure, i.e. the value for limit equilibrium [9-11]. Furthermore, Stamatopoulos and Velgaki [10] observed that for failure of gravity walls, a wedge in the backfill behind the wall reaches an active state, and that the wall and the backfill slide outward, and thus the soil-wall system consists really of two bodies: (a) the active soil wedge that slides with the inclination of least resistance in the backfill, and (b) the wall that slides along the soil-wall boundary in the foundation (Fig. 3b).

Stamatopoulos et al. [11] developed an analytical equation predicting the critical acceleration value of the soil-wall system of Fig. 3a and table 2, by solving the force equilibrium equations assuming a geometry consisting of two rigid blocks [15]. For a horizontal wall and backfill with inclination $\alpha_{\mathrm{B}-\mathrm{I}}$ and for only frictional resistance at both the backfill and the soilwall boundaries, this equation gives

$a_{c-i}=g A A_{B} / B B_{B}$

where $g$ is the acceleration of gravity

$$
\begin{aligned}
& A A_{b}=X G\left[\left(1+A_{i} B\right)(1+F D)-\left(B-A_{i}\right)(F-D)\right]-\frac{\left(D A_{i}-1\right)\left(B-A_{i}\right)[(1+F D)-G(F-D)]}{A_{i}} \\
& B B_{b}=X\left[\left(1+A_{i} B\right)(1+F D)-\left(B-A_{i}\right)(F-D)\right]-\frac{\left(D A_{i}-1\right)\left(1+A_{i} B\right)[(1+F D)-G(F-D)]}{A_{i}}
\end{aligned}
$$

and

$$
\begin{array}{lll}
\mathrm{X}=2 \mathrm{~W}_{\mathrm{W}} /\left(\mathrm{\gamma} \mathrm{H}_{\mathrm{o}}{ }^{2}\right), & \mathrm{D}=\tan \delta, & \mathrm{B}=\tan \varphi_{\mathrm{B}}, \\
\mathrm{G}=\tan \varphi_{\mathrm{W}}, & \mathrm{F}=\tan \varphi_{\mathrm{I}}, & \mathrm{A}_{\mathrm{i}}=\tan \alpha_{\mathrm{B}-\mathrm{i}}
\end{array}
$$

where the parameters $W_{W}, \gamma, H_{0}, \delta,\left(\alpha_{B c r-i}\right)$ are illustrated in Fig. $3, \varphi_{B}$ is the frictional resistance at the backfill, $\varphi_{w}$ is the frictional resistance at the foundation soil-wall boundary and $\varphi_{1}$ is the frictional resistance at the backfill soil-wall boundary.

The critical acceleration value $a_{c}$ corresponds to the critical rupture angle $\alpha_{\mathrm{Bcr}-\mathrm{i}}$ which is the value of $\alpha_{B-i}$, which minimizes $a_{c-i}$ in Eq. (1). As illustrated by [10], $a_{c-i}$ is a parabola in terms of $\left(\alpha_{B-i}\right)$, having a single well-defined minimum. It is inferred that estimating numerically $A_{i}$, and thus $\alpha_{\mathrm{Bcr}-\mathrm{i}}$ also, is a simple matter using, for example, the bisection method [16]. 
(a)

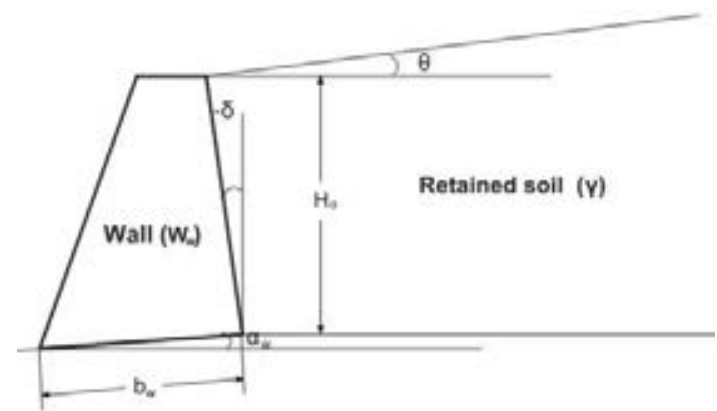

(b)

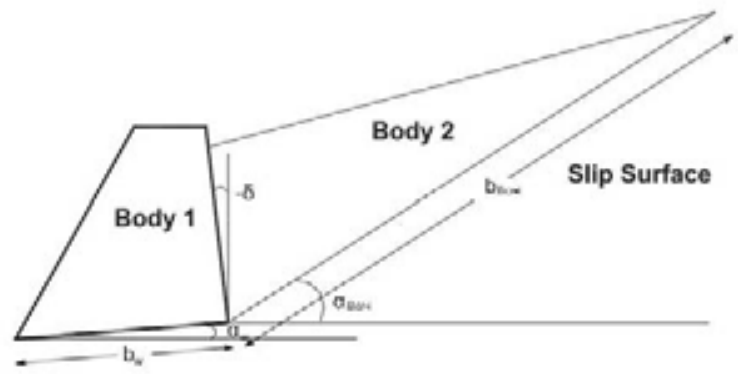

Figure 3: (a) Wall- retained soil geometry considered by [11] and (b) its simulation with a two-body model [11]

\begin{tabular}{|l|l|l|l|}
\hline & Parameter & Symbol & For Cantilever wall \\
\hline Wall & Weight & $\mathrm{W}$ & $\mathrm{W}=\mathrm{W}_{\mathrm{c}}+\gamma_{\mathrm{b}} \mathrm{H}_{\mathrm{c}}\left[\mathrm{b}+\mathrm{H}_{\mathrm{c}} \tan \left(\alpha_{\mathrm{i}}-\varphi_{\mathrm{b}}\right)\right] / 2$ \\
& Friction angle at base & $\varphi_{\mathrm{w}}$ & $\varphi_{\mathrm{c}}$ \\
\hline \multirow{3}{*}{ Backfill } & Height & $\mathrm{H}$ & $\mathrm{H}_{\mathrm{c}}$ \\
& Unit density & $\gamma$ & $\gamma_{\mathrm{s}}$ \\
& Friction angle & $\varphi_{\mathrm{b}}$ & $\varphi_{\mathrm{s}}$ \\
\hline \multirow{2}{*}{ Soil-wall interface } & Friction angle & $\varphi_{\mathrm{I}}$ & $\varphi_{\mathrm{s}}$ \\
& Inclination & $\delta$ (Fig. 5) & $\alpha-\varphi_{\mathrm{b}}$ \\
\hline
\end{tabular}

Table 2: Parameters which define the Stamatopoulos et al. [11] model considered in section 2.1 and the corresponding values for the cantilever wall of Fig. 2.

\subsection{The critical acceleration value of cantilever walls}

Figure 4 presents the mode of failure of cantilever walls proposed by Kloukinas et al. [3], where $\theta_{2}$ is related to $\theta_{1}$ and the frictional resistance of the backfill $\left(\varphi_{b}\right)$ as

$\theta_{2}=\theta_{1}-\varphi b$

Based on this mode of failure, it can be inferred that the sliding mechanism of cantilever walls can be simulated as a wall-backfill 2-body system of Fig. 3, where the first body corresponds to the cantilever wall and part of the backfill to the left of the slip segment AA' of Fig. 4 , and the second body corresponds to the backfill part to the right of the slip segment AA' of Fig. 4. Table 2 gives the equivalent values of the system of Fig. 3 solving the cantilever wall of Fig. 2. A condition needed for this solution, is that the slip surface passes through the ground surface of the backfill, or that

$$
\operatorname{Tan}\left(\alpha_{b-i-}-\varphi_{b}\right)<b / H_{c}
$$

It is inferred that equations (1) and the procedure outlined in section 2.1 with the values given in table 2 and the condition of equation (3) can be applied to estimate the critical acceleration value for relative motion of cantilever walls of the geometry of Fig. 2. A microsoft excel worksheet was programmed to estimate the critical acceleration value of cantilever walls of the geometry of Fig. 2, based on the procedure described above. 


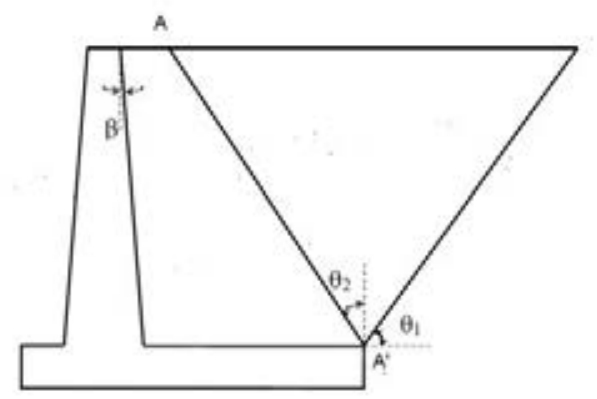

Figure 4: The mode of failure of cantilever walls proposed by Kloukinas et al. [3], where $\theta_{2}$ is related to $\theta_{1}$ with equation (2)

\section{PROPOSED METHOD PREDICTING THE SEISMIC DISPLACEMENT OF CANTILEVER WALLS CONSIDERING THE DYNAMIC RESPONSE OF THE SOIL PROFILE}

\subsection{State of the art: The Katsenis et al., $[13,14]$ model}

Katsenis et al. $[13,14]$ simulated the field configuration of a slope with a slip surface where seismic displacement may accumulate as a result of a horizontal shear wave of Fig. 5a with a 1-D dynamic system of 2 continuous bodies separated by a horizontal slip element. In particular, the Katsenis et al., $[13,14]$ model, illustrated in Fig. 5b and table 3, considers the 1-dimensional dynamic response of a horizontal soil profile of depth $\left(h_{1}+h_{2}\right)$ with a slip element at depth $h_{1}$. Different shear wave velocities $\left(\mathrm{V}_{\mathrm{s}-1}, \mathrm{~V}_{\mathrm{s}-2}\right)$, densities $\left(\rho_{1}, \rho_{2}\right)$ and damping $\left(\lambda_{1}, \lambda_{2}\right)$ may exist above and below the slip element. The slip element simulates the seismic displacement of the conventional sliding-block model, where its resistance is defined by the critical horizontal value $\left(a_{c}\right)$, for which relative movement in only one direction occurs.

The numerical code associated with the numerical model above is derived by extending the derivation proposed by [17]. When seismic displacement accumulates along the slip surface, the method simulates the independent movement of the two bodies, and thus the solution is "coupled". Additional options exist in the model where (a) the rotation of the slip surface with displacement is simulated by adjusting the critical acceleration value $\left(a_{c}\right)$ in terms of the accumulated seismic displacement and (b) the non-linear shear stress-stain response of the soil profile is simulated. However, these options are not applied in the present application.

When applying the model, if the soil profile of body $i$ is non-uniform, the average properties may be used [14]. In this respect, in the case of stratified deposit with $\mathrm{M}_{\mathrm{i}}$ sub-layers with height $\mathrm{H}_{\mathrm{k}-\mathrm{i}}$ and shear wave velocity $\mathrm{VS}_{\mathrm{k}-\mathrm{i}}$, it is recommended to estimate $\mathrm{Vs}_{\mathrm{i}}$ based on an equation proposed by Vijayendra et al. [18] as:

$$
V s_{i}=\frac{h_{i}}{\sum_{k=1}^{M_{i}} \frac{H_{k-i}}{V S_{k-i}}}
$$


(a)

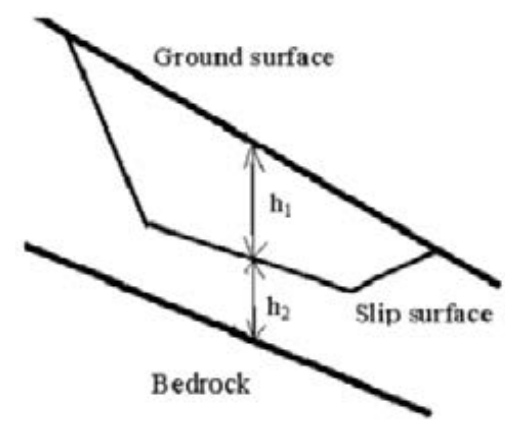

(b)

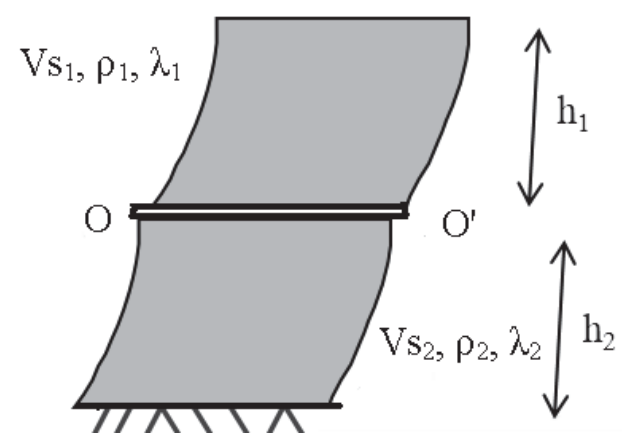

Figure 5: The Katsenis et al. [13, 14] model: (a) field configuration of a slope with a slip surface where seismic displacement may accumulate as a result of a horizontal shear wave, (b) simulation of (a) with a 1-D dynamic system of 2 continuous bodies separated by a horizontal slip element.

\begin{tabular}{|c|c|c|c|}
\hline & Parameter & Symbol & For Canteliver wall \\
\hline \multirow{3}{*}{$\begin{array}{l}\text { Upper (1) } \\
\text { Body }\end{array}$} & Height & $\mathrm{h}_{1}$ & $\mathrm{H}_{\mathrm{b}} / 2$ \\
\hline & Shear Wave velocity & $V_{\mathrm{s}-1}$ & $\mathrm{~V}_{\mathrm{s}-\mathrm{b}}$ \\
\hline & Density & $\rho_{1}$ & $\rho_{\mathrm{b}}$ \\
\hline Lower (2) & Height & $\mathrm{h}_{2}$ & $\mathrm{H}_{\mathrm{s}}+\mathrm{H}_{\mathrm{b}} / 2$ \\
\hline Body & $\begin{array}{c}\text { Shear Wave velocity } \\
\text { Density }\end{array}$ & $\begin{array}{l}V_{\mathrm{s}-2} \\
\rho_{2}\end{array}$ & $\begin{array}{c}\left(\mathrm{H}_{\mathrm{b}} / 2+\mathrm{H}_{\mathrm{s}}\right) /\left[\mathrm{H}_{\mathrm{b}} /\left(2 \mathrm{~V}_{\mathrm{s}-\mathrm{b}}\right)+\mathrm{H}_{\mathrm{s}} / \mathrm{V}_{\mathrm{s}-\mathrm{s}}\right] \\
\left(\mathrm{H}_{\mathrm{b}} / 2+\mathrm{H}_{\mathrm{s}}\right) /\left[\left[\mathrm{H}_{\mathrm{b}} /\left(2 \rho_{\mathrm{b}}\right)+\mathrm{H}_{\mathrm{s}} / \rho_{\mathrm{s}}\right]\right.\end{array}$ \\
\hline $\begin{array}{l}\text { Slip sur- } \\
\text { face }\end{array}$ & $\begin{array}{l}\text { Critical acceleration for } \\
\text { relative movement }\end{array}$ & $\mathrm{a}_{\mathrm{c}}$ & Specified in section 2.2 \\
\hline
\end{tabular}

Table 3: Parameters which define the Katsenis et al. $[13,14]$ model for the linear case. The corresponding values when this model is applied to simulate cantilever walls is also given.

\subsection{Proposed method}

In order to perform the numerical simulation of the seismic displacement of the cantilever wall of Fig. 2 considering the dynamic response of the soil profile both above and below the slip surface, we apply the 1-D coupled stick-slip dynamic model of Fig. 5b. The upper body of the dynamic system corresponds to the wall backfill above the slip plane. The lower body of the dynamic system corresponds to the wall backfill below the slip plane and the underlying soil profile. The critical acceleration of the stick-slip element for a cantilever wall was evaluated in section 3.

Based on the above, table 3 gives the corresponding when the Katsenis et al. [13, 14] model is applied to simulate the response of the cantilever wall of Fig. 2. As body 2 corresponds to both the wall backfill below the slip plane and the underlying soil profile, the average values are obtained using equation (3).

\section{SMART DESIGN OF CANTILEVER WALLS}

\subsection{Results of the Katsenis et al. [14] model}

Katsenis et al. [14] present the computed permanent seismic displacement $\left(\mathrm{u}_{\mathrm{f}}\right)$ for the Aegion 1995 seismic motion with $\mathrm{a}_{\mathrm{c}}=0.5 \mathrm{~m} / \mathrm{s} 2$ and (ii) Mid-Niigata Prefecture 2004 seismic motion with 
$a_{c}=3 \mathrm{~m} / \mathrm{s}^{2}$. Table 4 gives the characteristics of the input motions considered and the critical acceleration ac was selected as $0.5 \mathrm{~m} / \mathrm{s}^{2}$ and $3 \mathrm{~m} / \mathrm{s}^{2}$ for the input motions (i) and (ii) respectively, because they correspond to a rigid system having seismic displacement of about $5-10 \mathrm{~cm}$, which is the tolerable displacement value for typical structures.

In particular, they define

$\mathrm{Ts} 1=4 \mathrm{~h}_{1} / \mathrm{V}_{\mathrm{s}-1}$

Ts-ave $=4\left(\mathrm{~h}_{1} / \mathrm{V}_{\mathrm{s}-1}+\mathrm{h}_{2} / \mathrm{V}_{\mathrm{s}-2}\right)$

and Fig. 6 presents the computed permanent seismic displacement (uf) versus (a) Ts1/Tm for $\mathrm{h} 1+\mathrm{h} 2=30 \mathrm{~m}, \rho_{1}=\rho_{2}=2 \mathrm{Mg} / \mathrm{m}^{3}$ and $\lambda_{1}=\lambda_{2}=0.15$ (a) for the coupled case with $\mathrm{V}_{\mathrm{s}-2}=\mathrm{V}_{\mathrm{s}-1}, \mathrm{~h}_{2}=1 \mathrm{~m}$, $15 \mathrm{~m}, 25 \mathrm{~m}$, (b) Ts $1 / \mathrm{Tm}$ for $\mathrm{h}_{2}=15 \mathrm{~m}, \mathrm{~V}_{\mathrm{s}-2}=25,75,150,300,500,5000 \mathrm{~m} / \mathrm{s}$ and (c) Ts-ave $/ \mathrm{Tm}$ of the results of Figs (a), (b) for (i) the Aegion 1995 seismic motion with ac $=0.5 \mathrm{~m} / \mathrm{s} 2$ (ii) MidNiigata Prefecture 2004 seismic motion with ac $=3 \mathrm{~m} / \mathrm{s}^{2}$. Table 4 gives the characteristics of the input motions considered.

It can be observed that if uf is plotted in terms of the ratio Ts-ave/Tm, the scatter in results for different Vs2 and h2 decreases considerably. It is inferred that the dynamic effect on uf can partly be interpreted by relating uf to Ts-ave. In particular, similarly to the response predicted by [16], but by replacing Ts with Ts-ave, it can be observed that the dynamic response (a) does not exist for Ts-ave $=0$, (b) as Ts-ave increases, it produces maximum response when Ts-ave approximately when $\mathrm{Ts}$-ave $=\mathrm{Tm}$ and (c) as Ts-ave further increases, the dynamic response decreases towards zero.

\begin{tabular}{|c|c|c|c|c|c|c|}
\hline No & Earthquake Title & $\begin{array}{c}\mathrm{a}_{\max } \\
\left(\mathrm{m} / \mathrm{s}^{2}\right)\end{array}$ & $\begin{array}{c}\text { Predominant } \\
\text { Period }(\mathrm{Tp}) \\
(\mathrm{s})\end{array}$ & $\begin{array}{c}\text { Mean } \\
\text { Period }(\mathrm{Tm}) \\
(\mathrm{s})\end{array}$ & $\begin{array}{c}\text { Magnitude } \\
\text { Arias Intensity } \\
(\mathrm{cm} / \mathrm{sec})\end{array}$ \\
\hline 1 & Aegion, 1995 & 2.1 & 0.42 & 0.62 & 6.1 & 52 \\
\hline 2 & Mid-Niigata Prefecture, 2004 & 5.8 & 0.52 & 0.81 & 6.8 & 996 \\
\hline
\end{tabular}

Table 4. Characteristics of the input motions considered in Fig. 6. 
(i)

(a)

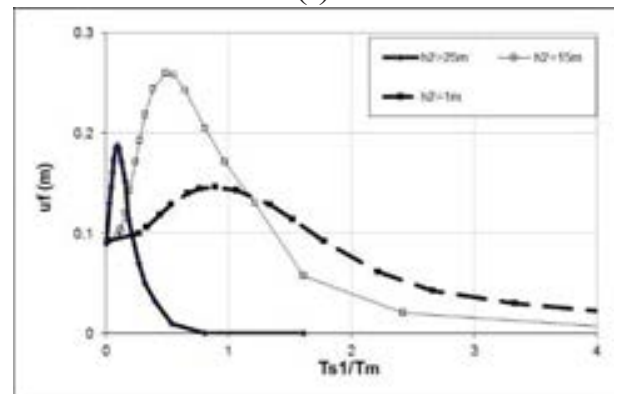

(b)

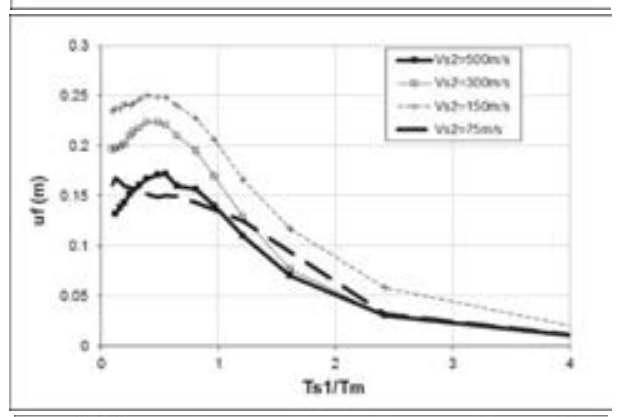

(c)

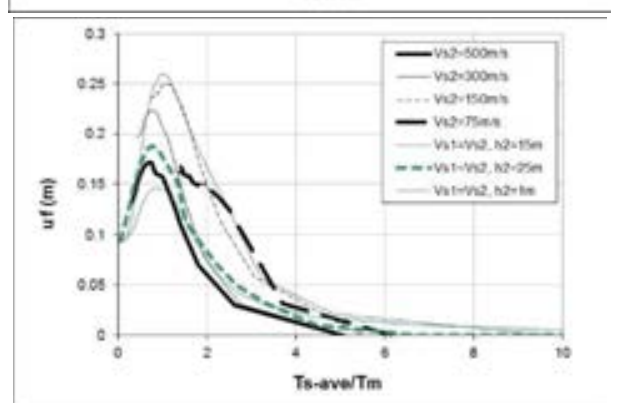

(ii)
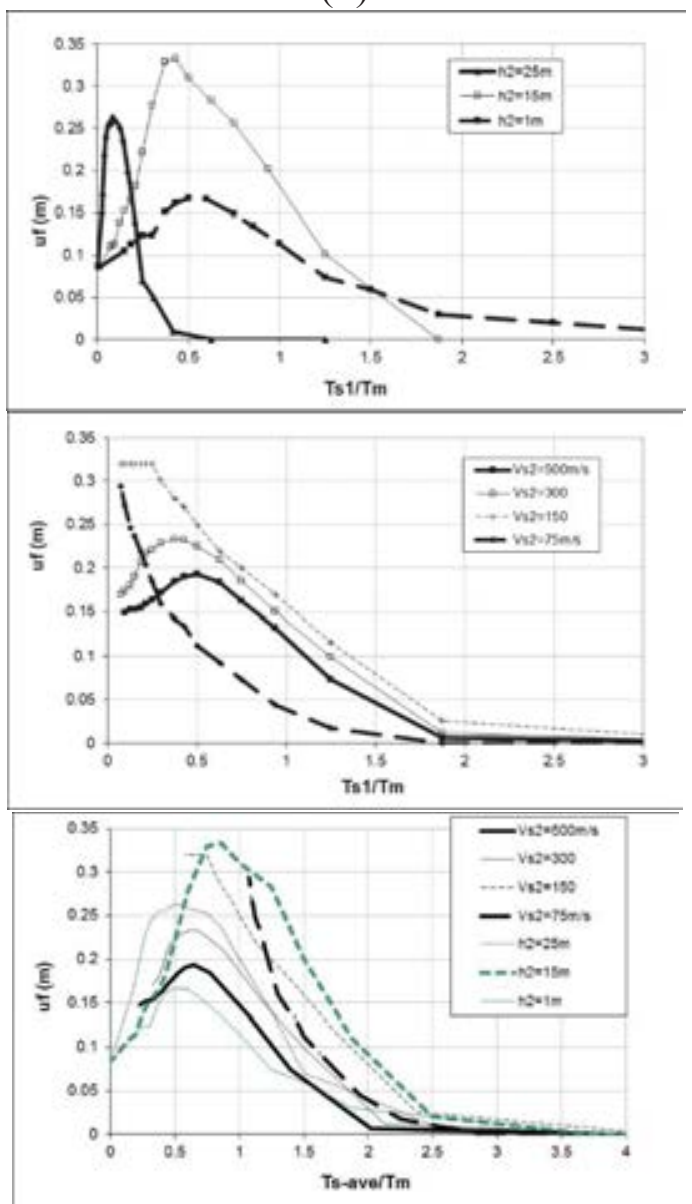

Fig. 6: The computed permanent seismic displacement $\left(u_{f}\right)$ versus (a) Ts1/Tm for $h_{1}+h_{2}=30 \mathrm{~m}, \rho_{1}=\rho_{2}=2$ $\mathrm{Mg} / \mathrm{m}^{3}$ and $\lambda_{1}=\lambda_{2}=0.15$ (a) for the coupled case with $\mathrm{V}_{\mathrm{s}-2}=\mathrm{V}_{\mathrm{s}-1}, \mathrm{~h}_{2}=1 \mathrm{~m}, 15 \mathrm{~m}, 25 \mathrm{~m}$, (b) for the coupled case with $\mathrm{h}_{2}=15 \mathrm{~m}, \mathrm{~V}_{\mathrm{s}-2}=75,150,300,500 \mathrm{~m} / \mathrm{s}$ and (c) $\mathrm{u}_{\mathrm{f}}$ versus Ts-ave/Tm of the results of Figs (a), (b). For (i) the Aegion 1995 seismic motion with $\mathrm{ac}=0.5 \mathrm{~m} / \mathrm{s}^{2}$ (ii) Mid-Niigata Prefecture 2004 seismic motion with ac=3m/s2. Table 4 gives the characteristics of the input motions considered.

\subsection{Indicative approximate criterion for de-amplification}

According to Fig 6, the seismic displacement decreases and takes values less than $0.05 \mathrm{~m}$, at large values of the ratio Ts-ave/Tm, and certainly when

Ts-ave $/ \mathrm{Tm}>4$

According to Eurocode 8 [21] at rock site the dominant period is less than 0.4 sec. It is inferred that de-amplification of the seismic response occurs when

Ts-ave $>1.6 \mathrm{~s}$

According to equations (4) and (5b), in the canteliver wall of Fig. 2, 
Ts-ave $=4\left(\mathrm{H}_{\mathrm{b}} / \mathrm{V}_{\mathrm{s}-\mathrm{b}}+\mathrm{h}_{\mathrm{s}} / \mathrm{V}_{\mathrm{s}-\mathrm{s}}\right)$

Thus, according to eqs. (6b) and (7), for de-amplification of the seismic response

$4\left(\mathrm{H}_{\mathrm{b}} / \mathrm{V}_{\mathrm{s}-\mathrm{b}}+\mathrm{h}_{\mathrm{s}} / \mathrm{V}_{\mathrm{s}-\mathrm{s}}\right)>1.6 \mathrm{~s}$

or

$$
\mathrm{H}_{\mathrm{b}} / \mathrm{V}_{\mathrm{s}-\mathrm{b}}>0.4 \mathrm{~s}-\mathrm{H}_{\mathrm{s}} / \mathrm{V}_{\mathrm{s}}
$$

Fig. 7 presents the limit shear wave velocity of the backfill $\left(\mathrm{V}_{\mathrm{s}-\mathrm{b}}\right)$ in terms of the height of the backfill $\left(\mathrm{H}_{\mathrm{b}}\right)$ and the ratio $\left(\mathrm{H}_{\mathrm{s}} / \mathrm{V}_{\mathrm{s}-\mathrm{s}}\right)$ of the underlying soil satisfying equation $(8 \mathrm{c})$. Figure 7 illustrates that the de-amplification effect of the seismic response can be crucial for loose backfill and if the soil underlying the wall is soft and deep. On the other hand, for small ratios of (Hs/Vs-s) of the underlying soil, smaller than 0.1, the de-amplification requires Vs-b values for the backfill, which are too small for practical application.

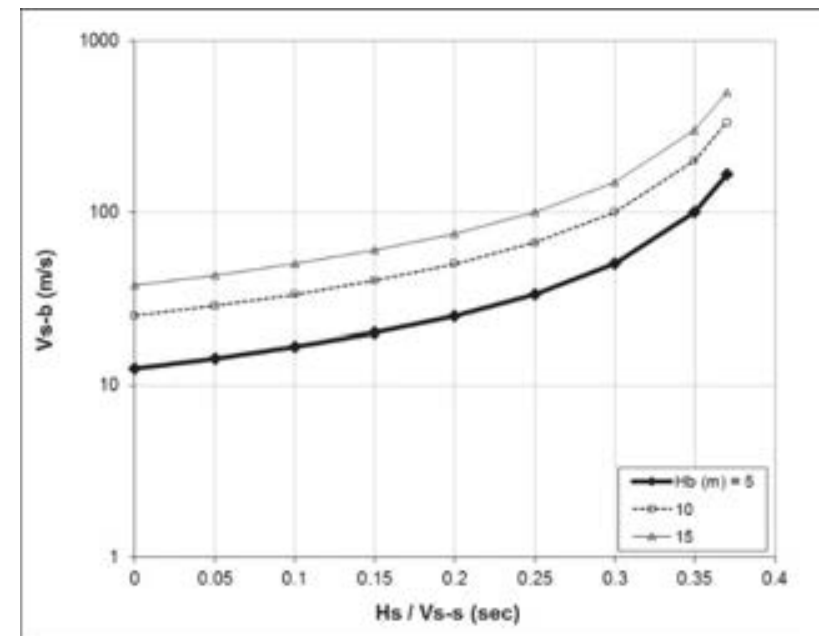

Figure 7: The limit shear wave velocity of the backfill $\left(\mathrm{V}_{\mathrm{s}-\mathrm{b}}\right)$ in terms of the height of the backfill $\left(\mathrm{H}_{\mathrm{b}}\right)$ and the ratio $\left(\mathrm{H}_{\mathrm{s}} / \mathrm{V}_{\mathrm{s}-\mathrm{s}}\right)$ of the underlying soil satisfying equation $(8 \mathrm{c})$.

\subsection{Proposed smart design method}

Typically, in cases where cantilever walls must be designed, the density of the backfill may be selected from loose to dense and this may affect the seismic displacement. Table 5 gives typical values of shear wave velocity [19], frictional resistance [20] and unit density in terms of soil density. Certainly dense construction is more costly and considering the soil strength along the slip surface produces less displacement. However, this may not hold in all cases: the previous section illustrated that considerable de-amplification may occur in softer layers.

The model proposed in section 3 above, which simulates in a cost-effective manner not only the mode of failure and corresponding displacement along the slip surface, but also the dynamic response of the backfill and underlying soil layer, allows the investigation and proposition of smart design of cantilever walls by performing relative parametric analyses. Such analyses are proposed to establish smart design of cantilever walls for given underlying soil conditions, and in particular the density of its backfill. Design seismic motions at the underlying bedrock, representative of the site under consideration, must be applied for this purpose. 


\begin{tabular}{|c|c|c|c|}
\hline & Loose (L) & Medium (M) & Dense (D) \\
$\varphi\left({ }^{\circ}\right)$ & 25 & 35 & 40 \\
$\mathrm{Vs}(\mathrm{m} / \mathrm{s})$ & 100 & 150 & 350 \\
$\gamma(\mathrm{kN} / \mathrm{m})$ & 18 & 20 & 22 \\
\hline
\end{tabular}

Table 5: Typical values of shear wave velocity [19], frictional resistance [20] and unit density for loose, medium and dense sands used in the analyses.

\subsection{Typical example}

In order to illustrate smart design of cantilever walls and its dependence to the underlying soil profile, we consider a cantilever wall with the typical properties given in table 6a above three different underlying soil profiles: $\mathrm{C} 1, \mathrm{C} 1, \mathrm{C} 3$ with properties given in table $6 \mathrm{~b}$. The backfill was considered to be in the loose, medium and dense states, with the corresponding properties of table 5. The seismic motion Mid-Niigata Prefecture 2004 was applied at the underlying rock.

(a) Wall

\begin{tabular}{|l|l|}
\hline Parameter & Value \\
\hline $\mathrm{Wc}(\mathrm{kN} / \mathrm{m})$ & 112.5 \\
$\mathrm{Hb}(\mathrm{m}) 6$ & 6 \\
$\mathrm{Hc}(\mathrm{m})$ & 5.5 \\
$\mathrm{~b}(\mathrm{~m})$ & 3 \\
$\varphi \mathrm{c}(\mathrm{o})$ & 25 \\
\hline
\end{tabular}

(b) Underlying soil profile: $\mathrm{C} 1, \mathrm{C} 1, \mathrm{C} 3$ cases

\begin{tabular}{|l|l|l|l|}
\hline Parameter & Value & & \\
Hs $(\mathrm{m})$ & 10 & 50 & $\mathrm{C} 3$ \\
Vs-s $(\mathrm{m} / \mathrm{s})$ & 100 & 100 & 300 \\
$\rho \mathrm{s}\left(\mathrm{T} / \mathrm{m}^{3}\right)$ & 2 & 2 & 2 \\
\hline
\end{tabular}

Table 6: Parametric analyses: Model parameters used: (a) Wall and (b) Underlying soil profile: C1, C1, C3 cases

Table 7 presents the results of the parametric analyses and Figure 8 plots the computed ratio of the seismic displacement when the backfill is in the loose and dense states ( $\mathrm{u}_{\mathrm{f}-\mathrm{loose}} / \mathrm{u}_{\mathrm{f} \text {-dense }}$ ), in terms of the ratio Hs/Vs-s of the underlying soil profile. It can be observed that if the ratio $\mathrm{Hs} / \mathrm{Vs}-\mathrm{s}$ is large, which corresponds to the case C2 where the soil underlying the wall is soft and deep, the loose backfill wall gives less seismic displacement and thus, for this case of seismic motion, it is recommended for optimum design.

\begin{tabular}{|c|c|c|c|}
\hline Case & Loose & Medium & Dense \\
\hline C1 & 0.88 & 0.7 & 0.61 \\
\hline C2 & 0.02 & 0.06 & 0.08 \\
\hline C3 & 0.7 & 0.65 & 0.36 \\
\hline
\end{tabular}

Table 7: Results of the parametric analyses: The final seismic displacement (in $\mathrm{m}$ ) in terms of the underlying soil type and the soil density of the backfill. 


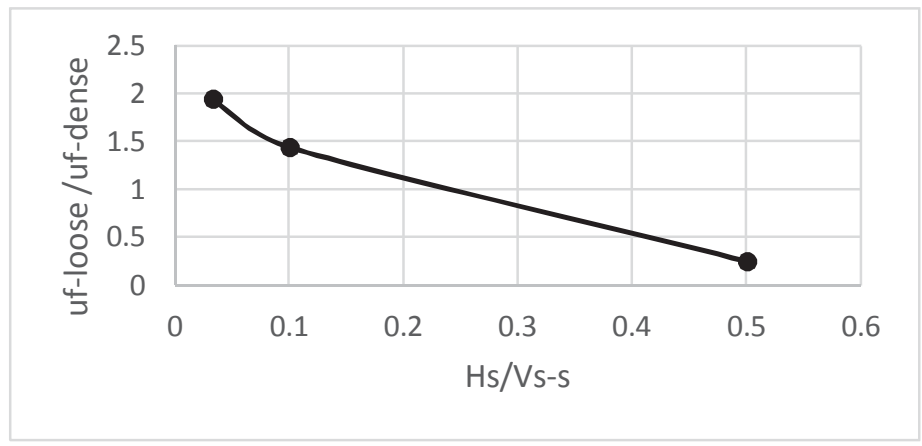

Figure 8: Results of the parametric analyses: The ratio of the seismic displacement when the backfill is in the dense and loose states in terms of the ratio Hs/Vs-s

\section{DISCUSSION}

The analysis of the present paper are initial findings of on-going research regarding smart design of cantilever walls. The theoretical work predicting the critical acceleration of cantilever walls may be generalized considering walls of more general geometry and strength. The proposed method predicting the seismic displacement of cantilever walls considering the dynamic response of the soil profile may be (i) improved by considering the non-linear soil response [22] and (ii) verified by the comparison of predictions with results of relative elaborate numerical analyses [11]. Furthermore, smart design of cantilever walls recommendations may be established more adequately by performing extensive parametric analyses where different soil profiles are studied and more seismic motions are applied.

\section{CONCLUSIONS}

The paper considers the cantilever wall of the geometry of Fig. 2 and (a) proposes a method predicting the critical acceleration value in section 2, (b) proposes a method predicting the seismic displacement considering the dynamic response of the soil profile in section 3 and (c) studies the de-amplification effect and proposes a methodology for smart design in section 4 . The work illustrated that the de-amplification effect of the seismic response may be crucial if the soil underlying the wall is soft and deep and in this case a wall with a looser backfill may be preferable.

\section{REFERENCES}

[1] Whitman R. V. Predicting earthquake-caused permanent deformations of earth structures, article on "Predictive Soil Mechanics", Thomas Telford, London, 729-741, 1993.

[2] Kloukinas P., Mylonakis G. Rankine Solution for seismic earth pressures on L-shaped retaining walls, 5ICEGEAt: Santiago, Chile, January, 2011

[3] Kloukinas P., Scotto di Santolo A., Penna A., Dietz M., Evangelista A., Simonelli L., Taylor C., Mylonakis G. Investigation of seismic response of cantilever retaining walls: 
Limit analysis vs shaking table testing. Soil Dynamics and Earthquake Engineering, Volume 77, October, 432-445, 2015.

[4] Newmark, N. M. Effects of earthquakes on dams and embankments. Geotechnique, 55 (2), 139-159, 1965.

[5] Ambraseys N. and Menu J. Earthquake induced ground displacements, Earthquake engineering and structural dynamics, 16, 7, 985-1006, 1998.

[6] Jibson R. W. Regression models for estimating coseismic landslide displacement Engineering Geology 91, 209-218, 2007.

[7] Mononobe, N. and Matsuo, H. On the determination of earth pressures during earthquakes, Proc., World Engineering Congress, 1929.

[8] Okabe, S. General Theory of earth pressures. J. of Japan Society of Civil Engineering, $12(1), 1926$.

[9] Richards R, Elms D. Seismic behaviour of gravity retaining walls. J Geotech Eng Division ASCE 105 (4),449-464, 1979.

[10] Stamatopoulos C. A, Velgaki E. G. Critical acceleration and seismic displacement of vertical gravity walls by a two body model. Fourth international conference on recent advances in geotechnical earthquake engineering and soil dynamics. San Diego, CA, March 26-31 (on CD), 2001.

[11] Stamatopoulos C.A., Velgaki E.G., Modaressi A., Lopez-Caballero F. Seismic Displacement of Gravity Walls by a Two-body Model. Bulletin of Earthquake Engineering volume 4, pages 295-318, 2006.

[12] Lin J.-S., and Whitman, R.V. Decoupling Approximation to the evaluation of earthquakeinduced plastic slip in earth dams. Earthquake Engineering and Structural Dynamics, 11: 667-678, 1983.

[13] Katsenis L.C., Stamatopoulos C.A., Panoskaltsis V.P. Non-linear dynamic seismic sliding movement of dry slopes, COMPDYN 2019, 7th International Conference on Computational Methods in Structural Dynamics and Earthquake Engineering, 24-26 June, Crete, Greece, 2019.

[14] Katsenis L.C., Stamatopoulos C.A., Panoskaltsis V.P. Prediction of large seismic sliding movement of slopes using a 2-body non-linear dynamic model with a rotating stick-slip element, February, Soil Dynamics and Earthquake Engineering, 2020.

[15] Stamatopoulos C. A., Velgaki E. and Sarma S. (2000). Sliding-block back analysis of earthquake-induced slides. Soils and foundations, The Japanese Geotechnical Society, Vol. 40, No. 6, Dec., 61-75, 2000.

[16] Dahliquist G, Bjorck A, (translated by Andeson N.). Numerical methods. Prentice-Hall Inc., NJ, 1974.

[17] Rathje E. M. and Bray J. D. An examination of simplified earthquake induced displacement procedures for earth structures. Can. Geotech. J. 36: 72-87, 1999

[18] Vijayendra, K.V., Prasad, S.K., Nayak, S. Computation of Fundamental Period of Soil Deposit: A Comparative Study, Oxford, UK, second edition, Indian Geotechnical Conference, December 16-18, 2010. 
[19] Kausarian H. Rock Mass, Geotechnical and Rock Type Identification Using SASW and MASW Methods at Kajang Rock Quarry, Semenyih, Selangor Darul Ehsan. Journal of Ocean, Mechanical and Aerospace, Science and Engineering-, Vol.26 December 30, 2015,

[20] Bery A. and Saad R. Tropical Clayey Sand Soil's Behaviour Analysis and Its Empirical Correlations via Geo-physics Electrical Resistivity Method and Engineering Soil Characterizations. International Journal of Geo-sciences, Vol. 3, No. 1, 111-116, 2012.

[21] European Standard (2003). Eurocode 8: Design of structures for earthquake resistance, Final Draft, prEN 1998-5, December, 2003.

[22] Vucetic M. And Dobry R. Effect of soil plasticity on cyclic response, Journal of the Geotechnical Division, ASCE, 117 (1), 1991. 